\title{
O ENIGMA DA ESFINGE METAFÓRICA
}

\author{
Paloma Catarina Zart
}

O mundo enrolava-se sobre si mesmo. MICHEL FOUCAULT.

\begin{abstract}
RESUMO ${ }^{(}$: Neste trabalho, resultado dos estudos realizados no Grupo de Estudos Lingüísticos (GEL), traz-se a problemática da metáfora como instrumento de fuga da obviedade, numa tentativa de ornamentação do texto. Como veremos a metáfora vai além do embelezamento, liberta o texto das amarras de uma significação primeira e possibilita uma nova constituição de sentido.
\end{abstract}

PALAVRAS-CHAVE: metáfora, significação, fuga.

\section{INTRODUÇÃO}

Era uma vez um texto, muito arteiro, que adorava se fingir de Esfinge e desafiar seu leitor. Como Esfinge, trazia o desafio de compreender um discurso, no qual se destacava uma palavra que, a primeira vista, causava um estranhamento ao leitor, pois abria o texto à outra possibilidade de leitura. $\mathrm{O}$ leitor, portanto, ficava um pouco confuso, como interpretaria aquela palavra, que tinha um sentido, mas ali, naquele contexto, tinha outro.

A Esfinge brincava de Vulcano, forjava, moldava, lapidava, polia o texto, entregando uma obra, não um conjunto de palavras. Nesta função artesanal, transformava o significado, entortava o sentido, desalinhava a retidão da significação.

Repleto de nervuras e curvas, o texto se apresentava ao seu leitor e lhe perguntava: decifras-me? Consegues passar por entre as árvores de meu bosque e encontrar as migalhas?

Porém, o texto, simpático ao seu desafiado, ia se entregando, descortinava o palco e se apresentava limpo, seco, rendia-se ao seu leitor, desde que esse soubesse lê-lo,

\footnotetext{
(c) Trabalho desenvolvido pela aluna do sexto semestre do curso de Letras - Inglês da UFSM a partir do Grupo de Estudos Lingüísticos (GEL) sob a orientação da Prof ${ }^{a}$. Dr. Amanda Eloina Scherer.
}

interpretá-lo e, para isso, fazia seu pobre decifrador olhar em volta, seguir o mapa como um pirata em busca do $X$ e encontrar seu tesouro: a metáfora.

\section{A colocação do enigma}

Trabalhamos com dois momentos da metáfora, seu uso em um período mais remoto e a sua compreensão contemporânea. $\mathrm{Na}$ retórica clássica, a metáfora é vista como simples transposição de termos símiles, uma escolha que se daria no nível do estético, da ornamentação. Como podemos ver em Aristóteles.

\footnotetext{
Metáfora é a transferência do nome de uma coisa para outra, ou do gênero para a espécie, ou da espécie para o gênero, ou de uma espécie para outra, ou por analogia. $^{1}$
}

Em seu momento atual, contrariamente, a metáfora é trabalhada na transferência de sentido, o enfoque está também na ornamentação, mas em um embelezamento no âmbito da construção do sentido que se daria na aproximação de palavras semelhantes permitindo uma substituição imprópria, alterando assim a função sintática e a classe gramatical da palavra.

Quando, em algum momento, dizemos "fulano é um porco", não dizemos que ele é, literalmente, um suíno, mas que apresenta características que possibilitam pensá-lo como um (DAVISON, 1992). Por isso, a metáfora repousaria no desvio e no empréstimo, alterando a significação primeira onde a interpretação do discurso se efetua. Entre o dito e o não dito do enunciado.

Não é a veracidade da metáfora que interessa, mas a construção de sentido que com ela fazemos, já que a metáfora apresenta

\footnotetext{
1 Texto original do séc. IV a.C.; a tradução utilizada foi publicada em 1999, citação p.63. Bibliografia completa nas referências.
} 
uma idéia falsa cuja símile é verdadeira. Pois, compreende-se a metáfora, além da interpretação literal do texto, em seu uso de similitudes, para compor um significado além do escrito, que nos permite vê-la como síntese de uma imagem.

Caso o discurso se forme sobre um plano cartesiano, onde o eixo sintagmático nos posiciona na estrutura da frase, no nível da palavra, enquanto que o eixo paradigmático nos guia à análise da frase, buscando sua compreensão além dos limites do texto, a metáfora estará sobre o eixo paradigmático, na construção do sentido, resultando da interferência ou do processo de autoria do texto.

Dizemos que a metáfora está sobre o eixo paradigmático, porque só podemos compreender um texto metafórico esquecendo - sentido literal, buscando novas possibilidades de explicação. Segundo Eco (1995), a interpretação da metáfora busca leis válidas para os contextos discursivos além do texto. Isto é possível, pois "toda expressão metafórica é identificada como tal porque, interpretada ao pé da letra, pareceria absurda e falsa" (idem). Por isso:

Somos assim levados a representar o discurso como jogo recíproco entre a palavra e a frase: a palavra preserva 0 capital semântico constituído pelos valores contextuais sedimentados em sua área semântica, e o que ela traz para a frase é um potencial de sentido, sendo que esse potencial não é informe: há uma identidade da palavra. (Ricoeur, 2000, p. 202).

A metáfora está no nível da palavra, pois, é uma palavra que substitui a outra alterando a significação primeira. Deste desvio resulta a relação entre o que é e o que parece. Expliquemos.

Quando, num texto, tem-se uma metáfora, a palavra que ocupa a lacuna semântica parece ser, o que remete a significação primitiva, mas ela, naquele momento é, ou seja, tem outra significação, que desloca seu sentido.

Isso nos remete à citação de Fontanier, trazida por Ricoeur:

O sentido é, relativamente a uma palavra, o que esta palavra nos faz entender, pensar e sentir por sua significação; e sua significação é o que ela significa, isto é, aquilo de que ela é signo, de que ela faz signo. (ibid, p. 86).

Como se perceberá nos exemplos a seguir, a metáfora recai sobre uma palavra ou expressão, que liberta o enunciado para uma nova significação. Lembrando Ricoeur:

É um enunciado inteiro que constitui a metáfora, mas a atenção concentra-se em uma palavra particular cuja presença se justifica que se considere o enunciado metafórico.(p. 135)

Assim a metáfora resulta da relação que o tropo possui com a totalidade da frase, pois, um ganha sentido com o outro. Esta relação entre palavra e frase nos remete a teoria de Black, citada por Ricoeur (2000) entre foco e quadro. Sobre o foco recai a atenção que nos leva a aparência/essência da palavra, a qual no quadro, ou seja, no contexto, abre um leque de possíveis sentidos.

Vejamos a obra de Velásquez, "As meninas", para melhor compreender a relação entre foco e quadro.

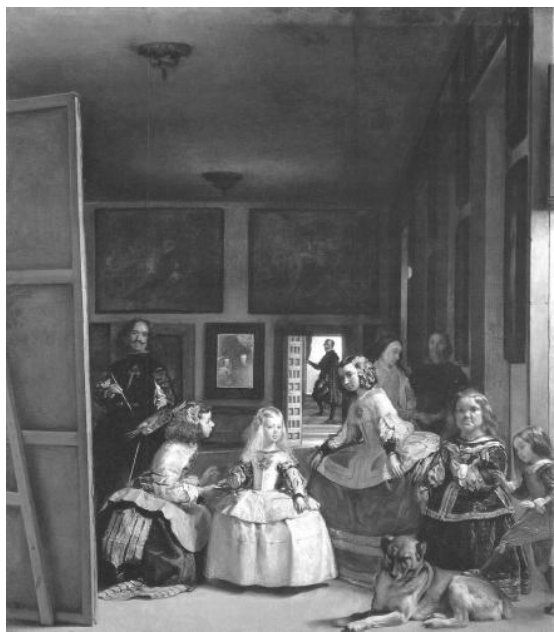

No centro da obra está a Infanta, seria mais um retrato da nobreza espanhola, não fosse o fato de, no canto, à esquerda, ter-se o auto-retrato do pintor. Lembremos ainda, a presença de suas majestades, ao fundo; o bisbilhoteiro, também ao fundo, e os acompanhantes da Infanta. Esse jogo de múltiplos olhares, incomum em retratos monásticos, dirige a atenção por caminhos divergentes criando tantos quadros quantos olhares são possíveis. Cada personagem representada deseja para si a atenção do observador, que como observou Foucault (1995) forma, juntamente com o pintor e a 
Infanta, os vértices de um triângulo, os vértices que guiam majoritariamente a cena.

\begin{abstract}
Nessa dispersão que ela reúne e exibe em conjunto, por todas as partes um vazio essencial é imperiosamente indicado: o desaparecimento necessário daquilo que o funda - daquela a quem ela se assemelha e daquele a cujos olhos ela não passa de semelhança [...] $\mathrm{E}$ livre, enfim, dessa relação que a acorrenta, a representação pode se dar como pura representação.(Foucault, 1955, p. 31).
\end{abstract}

A artimanha de Velásquez, ao criar um quadro mise-en-abyme, possibilita múltipla análise da obra, vai depender do ponto, ou melhor, do foco que se prioriza.

Bem como o jogo de olhares do quadro de Velásquez, que possibilitam ver a obra em partes, levando-a para o todo; a metáfora, é vista no âmbito da palavra, de modo a operar dentro de um enunciado inteiro, tornando todo o dito uma transferência de sentido. Ela começa, dentro do enunciado, com uma palavra e estende seu desvio ao resto da frase, pois, segundo Ricoeur (2000), a metáfora é resultado de um debate entre predicação e denominação, seu lugar na linguagem é entre as palavras e as frases. Como na obra velasquiana, ela disputa a atenção para criar uma teia de significações.

\section{A esfinge dissecada}

Voltemos nossa atenção para as similitudes foucaultianas, a saber: convenientia, aemulatio, analogia, e simpatia. Todas submetem idéias a uma aproximação, e nessa ordem apresentam um grau crescente de abordagem.

Comecemos pela convenientia, que está restritamente ligada à proximidade espaçotemporal dos semelhantes, geralmente unindo idéias que, de tão próximas, já quase não se pensam separadas. Foucault (1995) traz como exemplo a noção de alma e corpo. Não se pensa um corpo sem alma ou uma alma sem corpo, quando estes estão afastados já perderam sua materialidade. Mesmo não sendo a alma material ela a adquire pela sua aproximação com o corpo.

A aemulatio, por sua vez, vai mais longe e assemelha idéias que estão mais distantes, essa similitude acaba por exigir um esforço de abstração. A analogia seria uma similitude das outras duas similitudes, e não foge do conceito aristotélico de manifestação da metáfora, aproxima, portanto, a convenientia e a aemulatio. De acordo com Foucault (idem), seria uma analogia a construção da imagem dos vasos sangüíneos com um rio, ou da boca com Vênus, por ter os constituintes da primeira, em comum, a imagem de fluxo, de leito. E a segunda, por ser a boca que profere palavras de amor e Vênus a deusa de tal sentimento.

Finalmente a simpatia, como Zeus, rege as três similitudes, é ela quem permite as mais improváveis aproximações, e tem seu poder diminuído pela antipatia, que como o conselho dos deuses no Olimpo, barra a força da simpatia. Sem tal empecilho tudo seria fundido e perderia sua identidade.

As similitudes, portanto, podem ser consideradas como uma dissecação da metáfora, Foucault como bom anatomista, desvenda as entranhas e apresenta suas nuances.

Com isso nossa amiga esfinge brinca de esconde-esconde nas penumbras da floresta textual, porém vai deixando suas migalhas de pão, a fim de se fazer encontrada por quem a procura. Percebe-se a camaradagem da Esfinge, pois pôr em determinado lugar algo que não pertence naturalmente a ele conduz a uma observação mais detalhada do escrito.

Vejamos, portanto, como atua o texto brincalhão com sua marionete Esfinge.

\section{Elucidação do Enigma}

Trabalharemos três exemplos:

Exemplo 1:

Inquirido sobre sua raça, respondeu:

- A minha raça sou eu, João Passarinheiro.

Convidado a explicar-se, acrescenta:

- Minha raça sou eu. A pessoa é uma humanidade individual. Cada pessoa é uma raça, senhor polícia.

(Couto, 1998, p. 8).

A metáfora aqui opera na dualidade pessoa/humanidade. Quando João Passarinheiro intitula-se humanidade, traz a si toda a carga semântica da palavra. $\mathrm{Na}$ significação, primeira humanidade é:

1. Conjunto de características específicas à natureza humana; [...] 3. Conjunto de seres humanos; 4. Qualidade de quem realiza plenamente a 
natureza humana. (Houaiss, 2001, p. 1555).

\begin{abstract}
João Passarinheiro, em seu discurso, pega de empréstimo 0 substantivo humanidade transformando-o em predicativo do sujeito, dessa transferência resulta a compreensão da multiplicidade da posiçãosujeito, podendo ser pai, tio, avô, profissional. Para cada uma das posições, João apresenta um sujeito, uma característica peculiar. $O$ somatório das peculiaridades resulta num sujeito uno-plural, por isso ele se considera toda a humanidade. Esta sendo um conjunto, e também João o sendo, possibilita que a personagem assim se perceba.
\end{abstract}

O jogo metafórico de raça/eu ou homem/raça ocorre em um campo semelhante ao da metáfora pessoa/humanidade, mas em gesto diferente, pois, a designação de raça está inserida na de humanidade, restringindose, porém, em sua especificidade, uma vez que raça é, segundo Houaiss (2001):

2. Divisão tradicional e arbitrária dos grupos humanos, determinada pelo conjunto de caracteres físicos hereditários [...] 2. Conjunto dos seres humanos, pertencentes a cada um desses grupos. 3. O conjunto dos seres humanos, a humanidade [...] 6 . Coletividade de indivíduos que se diferenciados sua especificidade sociocultural, refletida principalmente na língua, religião e costumes; grupo étnico. 7. Grupo étnico em relação com a nação, a região. 8. A ascendência de um povo. ( p.2372).

Então, ao primeiro se denominar raça, João se posiciona num grupo menor, que o leva a um outro grupo mais abrangente. Quando João se diz raça, faz constituir a diferenciação entre ele e seu interlocutor. Vendo que não é compreendido, coloca-se no mesmo patamar do policial, igualando-se a este, ao se denominar humanidade, mas sempre mantendo a distância que os separa. Essa distância é a raça, visto que, como foi mostrada pela primeira significação da palavra, raça se refere a um grupo com as mesmas características. João admite a si duas classificações, a de raça, posicionando-se dentro de um clã, e a de humanidade, sendo, pois, seu clã pertencente à humanidade.

Pode-se pensar a fala de João como interseção de dois grupos, onde temos: de João.

No encontro dos grupos a constituição

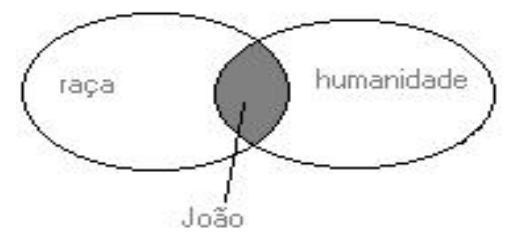

Exemplo 2:

La Lune, qui est le caprice même, regarda par la fenêtre pendant que tu dormais dans ton berceau, et se dit: "Cette enfant me plaît".

Et elle descendit moelleusement son escalier de nuages et passa sans bruit à travers les vitres. ${ }^{18}$ (Baudelaire, Les bienfaits de la lune)

Nossa atenção recai sobre a expressão escalier de nuages. A lua, agente da ação, utiliza-se de um instrumento, a escada, para alcançar seu objeto, a menina que dorme, porém, a escada da lua, não é de qualquer material, mas de nuvens. O fato de a escada ser de nuvens nos remete a imagem de filtro que estas assumem, pois, barram parte da luminosidade da lua, fazendo com que ela não agrida o sono da criança, apenas a ilumina parcialmente.

A menção da escada de nuvens nos leva a pensar na distância existente entre as duas personagens, lua e criança. Como uma pessoa que precisa de auxílio para alcançar algo, a lua faz uso da escada, ganhando assim um traço humano. A escada nos remete aos estratos da atmosfera, sendo que cada nuvem, no lugar do degrau, traz um dos estratos da abóbada celeste. Portanto, a luz da lua ilumina a criança com suavidade devido à distância entre elas e pelo cuidado da lua em relação à criança.

A expressão também reforça a idéia onírica do estado em que a criança se encontra; está inconsciente, nos domínios da fantasia, no imaginário do sono, onde as formas são vagas como é a imagem de uma escada feita de nuvens; qualquer estímulo mais brusco deforma a escada devido a sua grande fragilidade.

18 Versão eletrônica disponível em: www.gallica.bnf.fr acessado em 03/05/2006. - A lua, que é o capricho em pessoa, olha pela janela enquanto tu dormias em teu berço, e diz a si: "Esta criança me agrada". Ela desceu graciosamente sua escada de nuvens e passou sem fazer barulho entre os vidros. 
Exemplo 3:

Cette vie est un hôpital où chaque malade est possédé du désir de changer de lit. ${ }^{19}$ (Baudelaire, Any where out of the world)

Considerar a vida como um hospital remete a idéia de recuperação da plenitude da saúde, por ser o hospital um local de reabilitação. O constante desejo de mudança gerado pela insatisfação permanente do homem, faz com que, até uma pessoa debilitada busque outros limites. Pensar no desejo de mudança em uma vivência caracterizada como hospitalar apresenta um gosto tétrico pela vida. Nada parece mais prazeroso que sair do quarto comum para um centro de tratamento intensivo.

Mudar de leito, sendo indiferente um melhor ou pior, mostra um desconforto com a situação. Mudar, mudar sempre é um lema que vai além das possibilidades físicas. Ficar preso a uma cama, aqui servindo de sintetizador de um espaço delimitado que causa sofrimento, marca a insatisfação com o que se tem e a esperança que sustenta a vida.

Pelos exemplos, vemos que para compreendermos os textos, precisamos buscar instrumentos além dos próprios. Tudo está e, concomitantemente, não está dito nele. As imagens construídas resultam da caça por indícios de sentidos, os quais possibilitam ver os textos sobre diversos referenciais.

Segundo Orlandi (2001) o texto é um bólido de sentidos e parte em inúmeras direções em múltiplos planos significantes. A direção que o texto toma é dada pela textualidade, ou seja, pela relação que o texto tem consigo e com a exterioridade. (Orlandi, idem). A relação entre texto e exterioridade é feita pelo leitor, pelo seu jogo de olhares com o qual liga o dito no texto com o que traz em sua formação discursiva. O sentido, pois, reflete essa ligação entre texto/exterioridade/história.

Dessa rede de possibilidades, finitas, de sentido e significação a metáfora sai como um "mestre de cerimônias", apresentando os ambientes da festa, mas deixando a cargo de cada convidado a direção a ser tomada. O ambiente pode estar mais movimentado, lembrando uma intrincada rede de ligações feitas pelo leitor, ou relativamente vazio.
Quanto maior o número de pessoas no ambiente, maiores as possibilidades de se descobrir um proseador instigante, da mesma forma, a metáfora será mais instigante. A transferência de significados, portanto, é análoga à relação entre os sujeitos, assim a metáfora está para o texto como o interesse para os participantes do diálogo. Só encontra beleza num texto quem a procura.

Esta busca pode nos guiar à resolução da charada da Esfinge, ou nos fazer vítimas dela. Vai depender de conseguimos somar 0 texto às condições de produção, à história e ao discurso.

Seguir a sutil pista do pão em meio à penumbra da floresta exige mais que atenção, é preciso pensar além do escrito, ver além do horizonte, caçar o mito e derrotá-lo.

\section{REFERÊNCIAS BIBLIOGRÁFICAS}

ARISTÓTELES: Poética. In: Aristóteles. São Paulo: Nova Cultural, 1999.

COUTO, Mia: Cada homem é uma raça. Rio de Janeiro: Nova Fronteira, 1998.

DAVIDSON, Donald: "O que as Metáforas significam". IN: SACKS, Sheldon (org.) $\mathrm{Da}$ metáfora. São Paulo: Pontes. 1992.

ECO. Umberto: Os limites da interpretação. São Paulo: Perspectiva. 1995.

FOUCAULT, Michel: As palavras e as coisas. São Paulo: Martins Fontes. 7 ed. 1995.

ORLANDI, Eni Pucinelle: Análise do Discurso, princípios e procedimentos. Campinas: Pontes, 3 ed. 2001.

Interpretação: autoria, leitura e efeitos do trabalho simbólico. Petrópolis: Vozes, 3 ed. 2001.

RICOEUR, Paul: $A$ metáfora viva. São Paulo: Edições Loyola, 2000.

: "O Processo metafórico como Cognição, Imaginação e Sentimento". IN: SACKS, Sheldon (org.) Da metáfora. São Paulo: Pontes. 1992. 